\title{
Cancer Information Service
}

National Cancer Institute

\section{Source}

National Cancer Institute. Cancer Information Service. NCI Thesaurus. Code C16007.

A nationwide cancer information and education network sponsored by the $\mathrm{NCl}$. Provides

information on prevention, treatment, and ongoing clinical trials to cancer patients and their families, people at risk for cancer, and health professionals. 